\title{
Aplicação de Agentes BDI com Percepção Fuzzy em um Modelo Presa-Predador Fuzzy
}

\author{
Giovani Parente Farias ${ }^{2}$ \\ Graçaliz Pereira Dimuro ${ }^{2}$ \\ Antônio Carlos da Rocha Costa ${ }^{2}$
}

\begin{abstract}
Resumo: Este artigo introduz um modelo de percepção fuzzy para agentes BDI, com uma aplicação em uma versão fuzzy do problema presa-predador, onde o processo de decidir qual presa um predador deve atacar, com base na comparação de sua força com a da presa, é baseado em seu mecanismo de percepção fuzzy. Neste ambiente de informação imperfeita, consideram-se três tipos de predadores, um deles sendo o agente BDI com percepção fuzzy. Várias simulações foram realizadas para a análise comparativa dos comportamentos dos diferentes agentes predadores em dois tipos de ambientes: com ou sem competição entre predadores.
\end{abstract}

\begin{abstract}
This work introduces a model of fuzzy perception for BDI agents, with an application in a fuzzy-like pray-predator problem, where the process of deciding on which pray a predator should attack, based on the strength of the pray compared with its own strength, is based on its fuzzy perception mechanism. In this environment with imperfect information, we consider different types of predator agents, one of them being the BDI agent with fuzzy perception. Several simulations were realized for the comparative evaluation of the behaviors of different predator agents in two types of environments: with and without competition between predators.
\end{abstract}

\section{Introdução}

As diferentes arquiteturas de agentes encontradas na literatura [21] têm sido estabelecidas, em sua maioria, para tratar informações com base na lógica clássica, onde uma proposição ou é verdadeira ou é falsa.

$\mathrm{O}$ modelo de agentes BDI (Beliefs, Desires and Intentions), introduzido por Rao e Georgeff [21], é um modelo intencional de agentes bem conhecido na literatura. Este modelo baseia-se na representação das crenças (beliefs) do agente sobre os estados do mundo e um conjunto de desejos (desires), que identificam os estados que o agente tem como objetivos.

\footnotetext{
${ }^{2}$ Pós-Graduação em Modelagem Computacional, Centro de Ciências Computacionais, Universidade Federal do Rio Grande - FURG, \{giovanifarias, gracaliz, ac.rocha.costa\} @gmail.com

${ }^{1}$ Este artigo é versão estendida do trabalho apresentado no WESAAC 2010 e classificado como o melhor artigo do evento. Uma versão resumida do trabalho, em lingua inglesa, foi apresentada no LADS/MALLOW 2010, em Lyon.
} 
Por um processo de deliberação, o agente formula uma ou mais intenções (intentions) (considerados aqui como os estados que o agente se compromete a alcançar). $\mathrm{O}$ agente então constrói um plano para alcançar tais intenções (através de alguma forma de raciocínio meiofim), e executa-o. Após, o agente usa sua percepção sobre o ambiente (que pode incluir a si mesmo) para proceder à atualização de suas crenças.

Entretanto, em diversas situações, é possível que o ambiente onde o agente se insere seja de informação imperfeita, definido por Zadeh [29], como um ambiente de informação vaga, subjetiva, incompleta, ambígua, conflitante, parcial ou incerta.

Além disso, em diversas aplicações baseadas em agentes, verifica-se a necessidade de observar, modelar, quantificar e formalizar aspectos nebulosos, subjetivos ou qualitativos, tais como os diversos conceitos sociais complexos encontrados em problemas reais [11,22]. Conforme Zadeh [28, 29], "quanto mais de perto se analisa um problema do mundo real, mais difusa se torna sua solução".

Nesse contexto, surge a Lógica Fuzzy (LF), que é a lógica associada à Teoria dos Conjuntos Fuzzy, introduzida em 1965 por Zadeh [28]. A LF oferece uma forma natural de representar informações vagas e subjetivas comuns em um ambiente de informação imperfeita, baseando-se justamente na ideia de que vários aspectos no pensamento humano não são dados exatos, mas podem ser aproximados como classes de objetos nas quais a transição entre a pertinência/verdade e a não-pertinência/falsidade é gradual e não abrupta. Assim, a LF possibilita mecanismos de decisão baseados na ideia de que o raciocínio humano muitas vezes não segue a lógica bivalorada ou multivalorada, mas uma lógica com verdades fuzzy, conectivos fuzzy e regras de inferência fuzzy.

Este trabalho apresenta um modelo de agente BDI com um mecanismo de percepção fuzzy, tal que o agente possa tratar, de maneira mais adequada, as incertezas relativas a um ambiente de informação imperfeita, tal como um ambiente presa-predador fuzzy.

O modelo presa-predador tem sido muito utilizado em estudos sobre a dinâmica de populações, cuja formulação pode ser descrita pelas equações de Lotka-Volterra [1]. O ambiente simplificado introduzido neste trabalho foi inspirado no modelo presa-predador fuzzy apresentado em [19].

Este artigo está organizado como descrito a seguir. Na Seção 2 são discutidos trabalhos relacionados, no sentido de contextualizar e justificar o trabalho. Na Seção 3 são apresentados os conceitos básicos da LF, assim como o sistema de inferência fuzzy adotado neste trabalho. O ambiente de informação imperfeita inspirado no modelo Presa-Predador Fuzzy é introduzido na Seção 4, incluindo a nossa proposta para o mecanismo de percepção fuzzy do agente predador. A análise das simulações é discutida na Seção 5. A Seção 6 é a Conclusão. 


\section{Trabalhos Relacionados}

$\mathrm{Na}$ literatura existem várias referências ao uso da LF para possibilitar aos agentes mecanismos de decisão mais adaptáveis à realidade, provendo flexibilidade em ambientes complexos e dinâmicos.

Em [13], por exemplo, foi observado que modelos de agentes simples, como os que são normalmente utilizados nas ferramentas existentes, não são nem suficientes nem adequados para lidar com a incerteza e a subjetividade que devem ser considerados na análise de valores (p.ex., confiança) na sociedade humana. Por este motivo, esses autores utilizaram a LF para especificar os atributos dos agentes que representam indivíduos, a evolução das mentes desses agentes, a herança, o relacionamento e a similaridade entre indivíduos. Em [14] foi proposto um sistema fuzzy para modelar a dinâmica das relações de amizade em um modelo baseado em agentes que pode gerenciar relacionamentos sociais. Em [7], filtros fuzzy foram utilizados para modelar confiança em modelos sociais baseados em agentes.

Nos trabalhos de simulação social baseada em agentes apresentados em [10, 30], facetas e traços de personalidades humanas foram especificados (de acordo com o modelo Big $F_{i v e}^{1}$ ) como regras condicionais em agentes fuzzy (que são capazes de executar raciocínio aproximado qualitativo), para realizar simulação do comportamento humano. Já em [8], a LF foi utilizada para avaliação de trocas sociais entre agentes baseados em personalidades, propondo a análise das interações entre agentes com base na noção de equilíbrio fuzzy de trocas de serviços entre agentes.

Em [24] foi apresentada uma aplicação da LF na simulação de comportamentos humanos em redes sociais, representando elementos comportamentais, tais como estresse, motivação ou fadiga, e aspectos sociólogicos.

A LF foi utilizada em [9] para modelar o comportamento adaptativo de agentes no Dilema do Prisioneiro Repetido, para analisar a evolução da cooperação. Em [23] foi proposta uma representação fuzzy de avaliações para o sistema Repage, que adota uma teoria cognitiva de reputação.

Finalmente, no contexto de agentes BDI, nos trabalhos de Casali et al. [3] foi definido o modelo de agente BDI graduado, através de uma arquitetura baseada em sistemas multicontextos, que admite atitudes mentais (crenças, desejos e intenções) graduadas, em sentido similar ao da LF. Em [4], este modelo de agente BDI graduado foi utilizado pelos autores para especificar um agente para assistência a viagens, que ajuda turistas a escolher pacotes de férias.

Outros modelos híbridos de agentes, introduzindo algum tipo de "nebulosidade" ao modelo BDI, também devem ser mencionados. Uma arquitetura BDI Fuzzy para agentes sociais foi proposta em [17], com uma proposta inicial para a modelagem de sociedades

\footnotetext{
${ }^{1}$ O modelo Big Five, também referido como modelo OCEAN, considera cinco dimensões de traços de personalidades (Openness, Conscientiousness, Extraversion, Agreeableness and Negative emotions) [5, 15].
} 
cooperativas de agentes, apontando para as condições sociais necessárias para os agentes formarem intenções e ações conjuntas. Em [16], foi proposto um modelo híbrido de agente BDI para operações em terminais de containers, que estendem as características de aprendizagem e adaptabilidade do modelo tradicional com redes neurais e sistemas de inferência neuro-fuzzy, possibilitando a melhora no processo de tomada de decisão em ambientes complexos e dinâmicos. Outros trabalhos com agentes BDI e redes neurais fuzzy possibilitaram aplicações em veículos submersos autônomos [12], onde há uma rede neural de vários níveis, onde um deles é o de elaboração de intenções fuzzy a partir das crenças e desejos do agente. Agentes BDI com raciocínio fuzzy foram apresentados em [25], com uma posterior aplicação em redes sensoriais sem fio [26].

Assim, sabe-se que a LF vem sendo bastante utilizada em simulações baseadas em agentes e que também há interessantes trabalhos com modelos BDI híbridos. Observa-se, entretanto, que embora sistemas de percepção fuzzy tenham sido empregados em agentes e, principalmente, em robots ${ }^{2}$, ainda não existe um modelo BDI acoplado a um mecanismo de percepção fuzzy, no sentido proposto neste trabalho, onde seja possível analisar a influência da percepção fuzzy na operação do agente BDI e em sua tomada de decisão.

\section{Lógica Fuzzy e os Sistemas Baseados em Regras Fuzzy}

Considere um universo $U$, dado por um conjunto clássico qualquer. Um subconjunto fuzzy $F$ de $U$ é definido como um conjunto de pares ordenados

$$
F=\left\{\left(x, \varphi_{F}(x) \mid x \in U\right\},\right.
$$

onde $\varphi_{F}: U \rightarrow[0,1]$ é a função de pertinência que indica o grau de pertinência de cada elemento $x \in U$ ao subconjunto fuzzy $F$ de $U$. Observa-se que $\varphi_{F}(x)=1$ e $\varphi_{F}(x)=0$ indicam, respectivamente, a pertinência plena e a não pertinência do elemento $x$ a $F$.

Em LF, explora-se o uso de variáveis linguísticas, cujos valores são termos linguísticos, interpretados como subconjuntos fuzzy. Por exemplo, a temperatura pode ser uma variável linguística assumindo valores baixa, média e alta, descritos por intermédio de conjuntos fuzzy, representados pelas funções de pertinência da Figura 1.

Os conetivos lógicos da Lógica Clássica foram estendidos para a LF. As extensões da conjunção e da disjunção clássica, por exemplo, são obtidas por meio das normas e das conormas triangulares, denominadas, respectivamente, de t-normas e $t$-conormas, e definidas como famílias de operadores binários $\Delta, \nabla:[0,1] \times[0,1] \rightarrow[0,1]$, que são monotônicos, comutativos e associativos, se comportam, respectivamente, como a conjunção e a disjunção clássica nos extremos do intervalo $[0,1]$.

Sistemas de inferência fuzzy são modelos não lineares que descrevem a relação de entrada-saída de um sistema real, utilizando uma família de construções linguísticas do tipo

\footnotetext{
${ }^{2}$ Veja, p.ex, os trabalhos em [6], onde a percepção fuzzy é utilizada para melhorar a navegação de robots, e em [18], que usa a percepção fuzzy em robots para melhorar a credibilidade na expressão de emoções.
} 


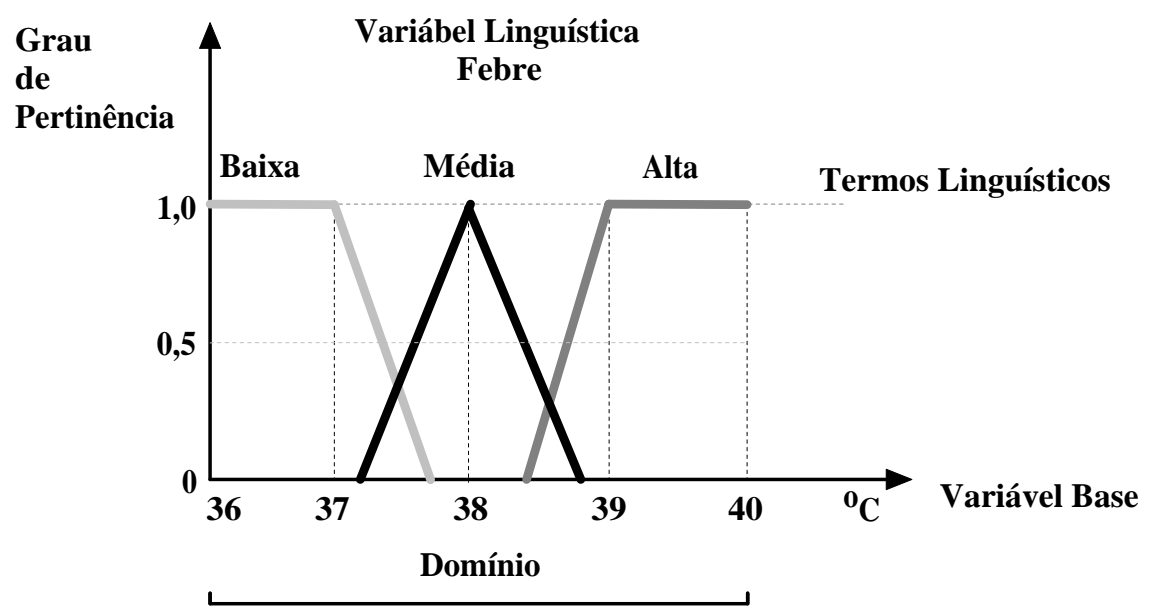

Figura 1. Variável linguística temperatura e seus termos linguísticos

Se-então e os mecanismos de inferência da LF. Em geral, um controlador fuzzy apresenta quatro componentes, mostrados na Figura 2:

- Módulo de Fuzzificação: mapeia os valores crisp de entrada do sistema em graus de pertinência dos conjuntos fuzzy que representam os termos linguísticos das variáveis linguísticas relacionadas.

- Base de Regras Fuzzy: composto pelas proposições fuzzy que modelam o sistema real, descritas na forma Se-então, de acordo com as informações de um especialista. A base de regras descreve relações entre as variáveis linguísticas, para serem utilizadas na máquina de inferência fuzzy.

- Módulo de Inferência Fuzzy: fornece a saída a partir de cada entrada fuzzy e da relação definida pela base de regras, através de métodos de inferência fuzzy.

- Módulo de Defuzzificação (opcional): processo utilizado para converter o conjunto fuzzy de saída em um valor crisp de saída do sistema.

Entre os diversos métodos disponíveis para inferência fuzzy, neste trabalho adota-se o método de Kang-Takagi-Sugeno (KTS) [27], onde cada regra fuzzy representa o modelo local do sistema real que está sendo considerado ${ }^{3}$. A $k$-ésima regra de um sistema KTS com vetor de entrada $X=\left(x_{1}, \ldots, x_{N}\right)$ e saída $z$ apresenta a forma geral:

$$
\text { Se }\left(x_{1} \text { é } A_{1, k}\right) \text { e } \ldots \text { e }\left(x_{N} \text { é } A_{N, k}\right) \text { então } z=f_{k}(X) \text {, }
$$

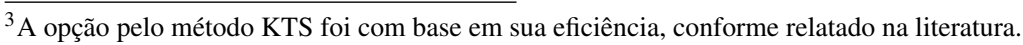




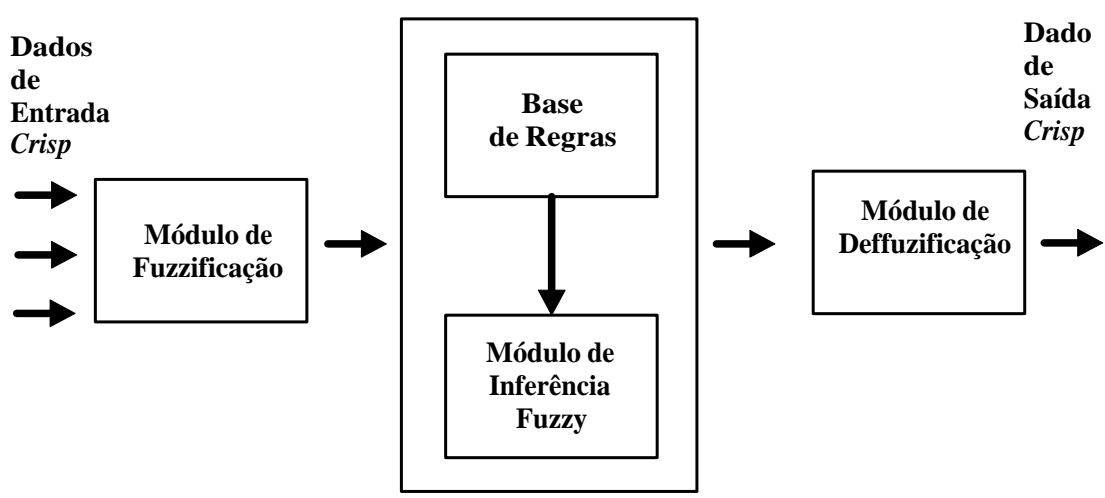

Figura 2. Esquema geral de um controlador fuzzy

onde os termos linguísticos $A_{n, k}(n=1, \ldots, N)$ nos antecedentes das regras representam conjuntos fuzzy com funções de pertinência $\varphi_{n, k}$, os quais são usados para particionar os domínios das variáveis de entrada em regiões que se sobrepõem. As funções $f_{k}$ nos consequentes das regras são usualmente polinômios de primeira ordem da forma:

$$
f_{k}\left(x_{1}, \ldots, x_{N}\right)=b_{0, k}+b_{1, k} x_{1}+\ldots, b_{N, k} x_{N} .
$$

Para uma dada entrada $X=\left(x_{1}, \ldots, x_{N}\right)$, o grau de satisfação da $k$-ésima regra avalia a compatibilidade da entrada $X$ com o antecedente da regra e determina a contribuição da resposta da regra $z=f_{k}\left(x_{1}, \ldots, x_{N}\right)$ para a saída geral do modelo. O grau de ativação da $k$-ésima regra é expressado como:

$$
w_{k}\left(x_{1}, \ldots, x_{N}\right)=\triangle_{1}\left(\varphi_{A_{1}, k}\left(x_{1}\right), \ldots, \varphi_{A_{N}, k}\left(x_{N}\right)\right),
$$

onde $\Delta_{1}$ é uma t-norma. Neste trabalho, $\Delta_{1}$ é a t-norma do Mínimo (denominada de t-norma de Gödel), e, então a Eq. 4 resulta em:

$$
w_{k}\left(x_{1}, \ldots, x_{N}\right)=\min \left\{\varphi_{A_{1}, k}\left(x_{1}\right), \ldots, \varphi_{A_{N}, k}\left(x_{N}\right)\right\} .
$$

A saída geral de um modelo fuzzy KTS de primeira-ordem normalizado com $K$ regras é dada por:

$$
z=\frac{\sum_{k=1}^{K} \Delta_{2}\left(w_{k}\left(x_{1}, \ldots, x_{N}\right), f_{k}\left(x_{1}, x_{2}, \ldots, x_{N}\right)\right)}{\sum_{k=1}^{K} w_{k}\left(x_{1}, \ldots, x_{N}\right)},
$$

onde $\Delta_{2}$ também é uma t-norma. Neste trabalho, $\Delta_{2}$ é a t-norma do Produto, tal que a Eq. 6 resulta em: 


$$
z=\frac{\sum_{k=1}^{K} w_{k}\left(x_{1}, \ldots, x_{N}\right) \cdot f_{k}\left(x_{1}, x_{2}, \ldots, x_{N}\right)}{\sum_{k=1}^{K} w_{k}\left(x_{1}, \ldots, x_{N}\right)} .
$$

Observa-se que o método KTS dispensa a etapa de defuzzificação.

\section{O Ambiente Presa-Predador Fuzzy}

Em [19], Peixoto et al. introduziram um sistema baseado em regras fuzzy para elaborar um modelo presa-predador específico para estudar a interação entre "pulgões" (as presas) e "joaninhas" (os predadores) em citricultura ${ }^{4}$. Pela falta de informação sobre o fenômeno, ao invés de utilizar as equações diferenciais usuais características dos modelos determinísticos, os autores introduziram uma abordagem fuzzy para analisar este problema específico.

No presente trabalho, inspirados nesta abordagem fuzzy para o modelo presa-predador, foi desenvolvida uma simulação, baseada em sistemas multiagente BDI, para analisar a habilidade de um predador com percepção fuzzy em sobreviver em um ambiente de informação imperfeita, onde a idade e o peso de uma presa (e do próprio predador fuzzy) são informação vagas para o predador fuzzy. Entretanto, tal informação é crucial para o predador avaliar sua força em comparação com a força de uma certa presa, e, portanto, para estimar a probabilidade de sucesso de seu ataque a tal presa, que foi estipulada (para fins de realização de exemplos de simulação) em:

$$
\operatorname{Prob}=\left(50+\frac{P R S L-P Y S L}{2}\right) \%,
$$

onde PRSL (PredatoR Strength Level) e PYSL (Prey Strength Level) são os níveis de força de predador e de presa, respectivamente. A Tabela 1 apresenta exemplos do cálculo desta probabilidade.

Tabela 1. Exemplos do cálculo da probabilidade de sucesso

\begin{tabular}{ccccccc}
\hline PRSL & 50 & 30 & 99 & 01 & 20 & 78 \\
PYSL & 50 & 90 & 01 & 99 & 20 & 52 \\
Prob $(\%)$ & 50 & 20 & 99 & 01 & 50 & 63 \\
\hline
\end{tabular}

Assume-se que o alimento sempre está disponível para as presas, que estão distribuídas em uma grade, e que o predador perde peso enquanto se movimenta aleatoriamente para

\footnotetext{
${ }^{4}$ Os pulgões são considerados os agentes transmissores da Morte Súbita de Citrus, uma doença que afeta as laranjeiras no Brasil.
} 
procurar presas, mas ele perde muito mais peso por cada ataque mal sucedido (ao contrário, ele ganha peso se seu ataque é bem sucedido). Então, a sobrevivência do predador depende de suas decisões sobre atacar ou não qualquer presa que ele encontre durante a sua vida. Esta decisão é baseada na informação imperfeita sobre peso e idade que o agente percebe através de seu mecanismo de percepção fuzzy, que utiliza um sistema de inferência fuzzy para determinar o seu nível de força, assim como o nível de força de uma presa, em cada encontro.

\subsection{O Predador}

O predador é um agente BDI com crenças sobre os seguintes parâmetros: idade, peso e nível de força. Os dois primeiros o agente percebe através de seu mecanismo de percepção. O último é estimado por ele considerando idades e pesos percebidas. As habilidades do predador são:

- Movimento aleatório em cada instante de tempo para tentar encontrar presas;

- Percepção de sua idade e peso, assim como as idades e pesoa de presas;

- Estimação de seu nível de força e dos níveis de forças de presas (comparando ambos os valores);

- Tomada de decisão com relação aos ataques a presas, que leva em conta se a probabilidade de sucesso, dada na Eq. 8, satisfaz Prob $>50 \%$, significando que o predador considera que o seu nível de força é maior que o da presa.

As restrições da vida do predador são:

- A cada movimento o predador perde uma quantidade fixa de peso, denominada de taxa de emagrecimento, e tem sua idade incrementada por um valor fixo, denominado de taxa de envelhecimento.

- A cada ataque bem sucedido (ataque no qual o predador ganha da presa), o predador ganha uma quantidade fixa de peso, denominada de recompensa; caso contrário, ele perde uma quantidade fixa de peso, denominada de punição.

- Se o predador atingir o peso mínimo (1 kg), ele morre por fraqueza; se atingir a idade máxima (50 anos), ele morre por velhice.

4.1.1 O Agente Predador Fuzzy (PF). O PF é um agente BDI com um mecanismo de percepção fuzzy diretamente conectado à FRC (Função de Revisão de Crença) de sua arquitetura BDI, conforme esquematizado na Fig. 3. Sempre que encontra uma presa, o mecanismo de percepção fuzzy do PF recebe como entradas o peso e a idade da presa, percebidos através dos sensores não precisos do PF. Então, usando o sistema de inferência KTS (como mostrado na Figura 4), o predador pode inferir o nível de força da presa, atualizando suas crenças. Em seguida, o mecanismo de percepção fuzzy do PF recebe como entrada o peso e a idade do próprio $\mathrm{PF}$, também percebidos através dos seus sensores não precisos. Novamente, usando 


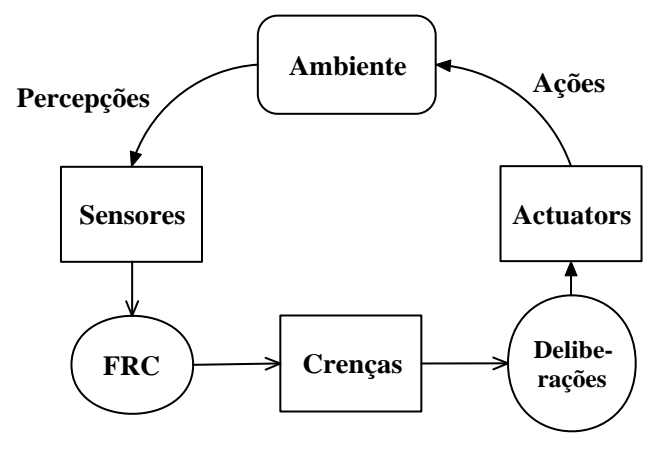

Figura 3. O modelo BDI com o módulo de percepção fuzzy

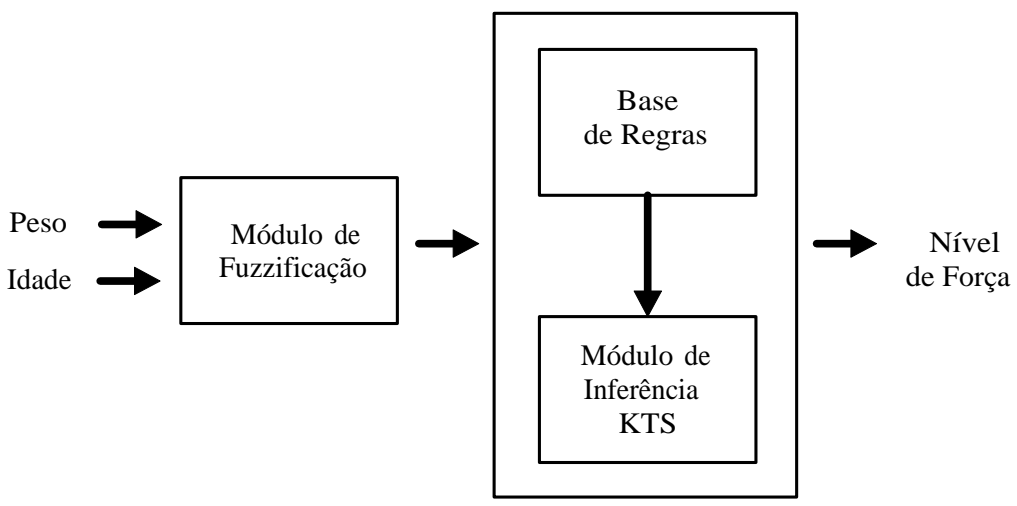

Figura 4. Arquitetura do sistema KTS para o cálculo do nível de força

o sistema de inferência KTS, o predador avalia seu próprio nível de força, atualizando suas crenças. Após, o predador toma a decisão de atacar ou não a presa encontrada. O predador BDI Fuzzy só irá atacar presas com o nível de força menor ou igual ao seu.

Assim, as variáveis linguísticas de entradas consideradas são idade e peso, e a de saída é o nível de força. Para essas variáveis, atribuiram-se termos linguísticos, cada um deles com funções de pertinência do tipo trapezoidal, representadas graficamente nas Figuras 5, 6 e 7.

Por meio da análise do conjunto dos dados envolvendo as variáveis mencionadas, estabeleceu-se uma base de conhecimento com regras linguísticas, apresentada na Tabela 2. A Tabela 3 apresenta a base de regras para o método KTS do modelo de percepção fuzzy do agente $\mathrm{PF}$, cada uma com duas entradas (idade, peso) $\in \mathbb{R}^{2}$ e a saída $z \in \mathbb{R}$, onde jovem, adulto, velho, muito leve, leve, médio, pesado e muito pesado são subconjuntos fuzzy de $\mathbb{R}$. 


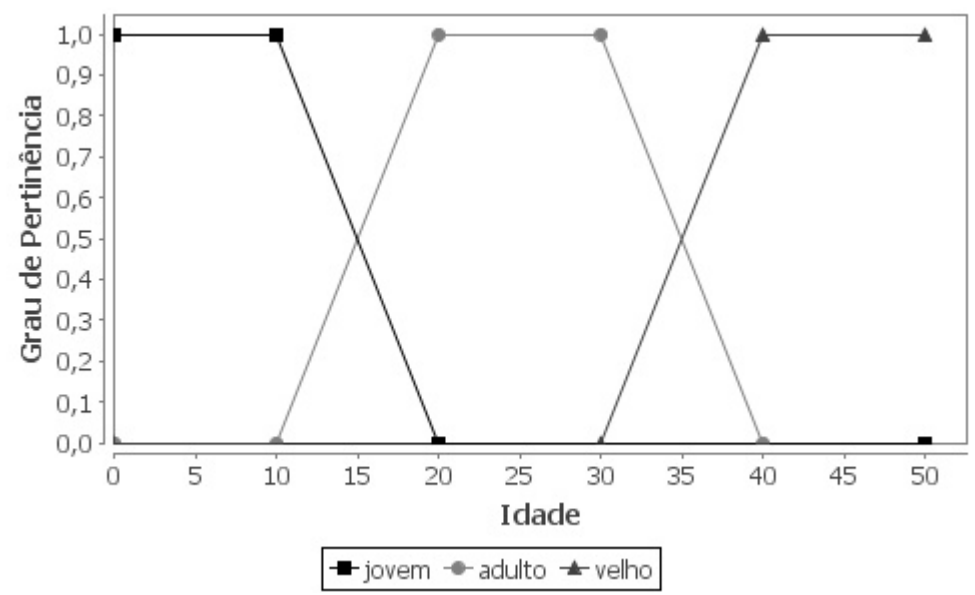

Figura 5. Variável linguística idade

Exemplo 1 Para exemplificar a utilização do método de inferência KTS no modelo de percepção fuzzy do predador, considera-se os seguintes valores crisp de entrada: idade $=16$ e peso $=84$. Esses valores são fuzzificados, considerando seus graus de pertinência em relação aos subconjuntos fuzzy que definem essas duas variáveis de entrada, dados na Figura 6. Assim, o valor idade $=16$ é considerado jovem com grau $\varphi_{\text {jovem }}(16)=0,4 e$ adulto com grau $\varphi_{\text {adulto }}(16)=0,6$. $O$ valor do peso $=84$ é avaliado como pesado com grau $\varphi_{\text {pesado }}(84)=0,6$ e muito pesado com grau $\varphi_{\text {muito_pesado }}(84)=0,4$. Cada combinação desses conjuntos acionados pelos valores de entrada ativam algumas regras na base de conhecimento. Neste caso, foram acionadas 4 regras, a saber, $R_{4}, R_{5}, R_{9}$ e $R_{10}$ da base de regras (Tabela 3). Pela Eq. 5, calcula-se o grau de ativação de cada uma dessas regras, p.ex., $w_{4}=\min \left\{\varphi_{\text {jovem }}(16), \varphi_{\text {pesado }}(84)\right\}=0,4$. Assim, tem-se que $w_{5}=0,4, w_{9}=0,6$ and $w_{10}=0,4$. Pela Eq. 7, obtém-se a saída geral do processo, onde $f_{4}, f_{5}, f_{9}$ e $f_{10}$ são calculadas pela Tabela 3 :

$$
z=\frac{w_{4} f_{4}(16,84)+w_{5} f_{5}(16,84)+w_{9} f_{9}(16,84)+w_{10} f_{10}(16,84)}{w_{4}+w_{5}+w_{9}+w_{10}}=74,
$$

que representa o nível de força.

4.1.2 O Agente Predador Crisp (PC). O Predador Crisp (PC) é um agente BDI que não considera que a informação percebida do ambiente (incluído a si próprio) seja vaga ou incompleta. Seu mecanismo de percepção é inspirado no controlador fuzzy do PF, mas, ao invés de usar subconjuntos fuzzy para modelar os valores das varáveis linguísticas de 


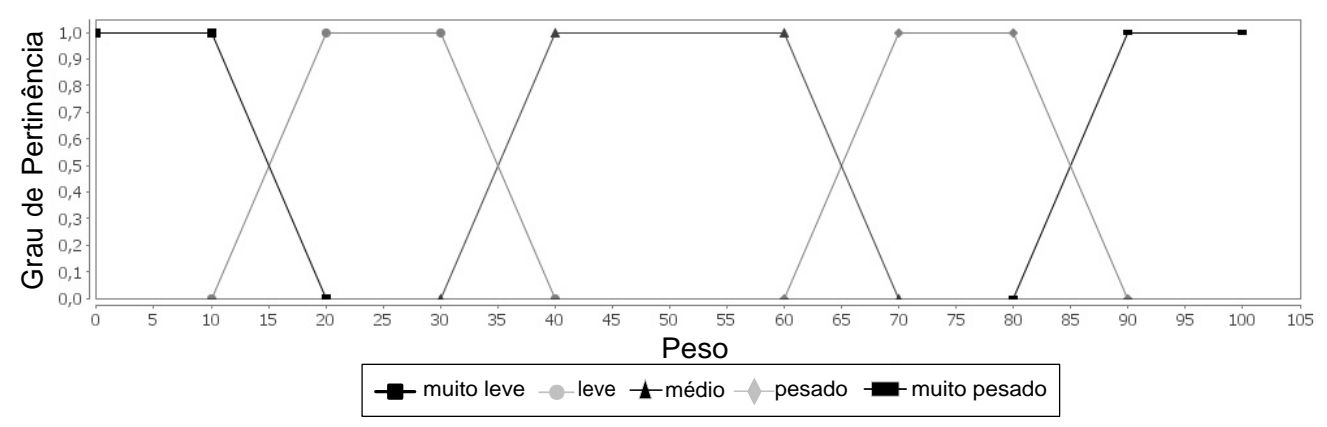

Figura 6. Variável linguística peso

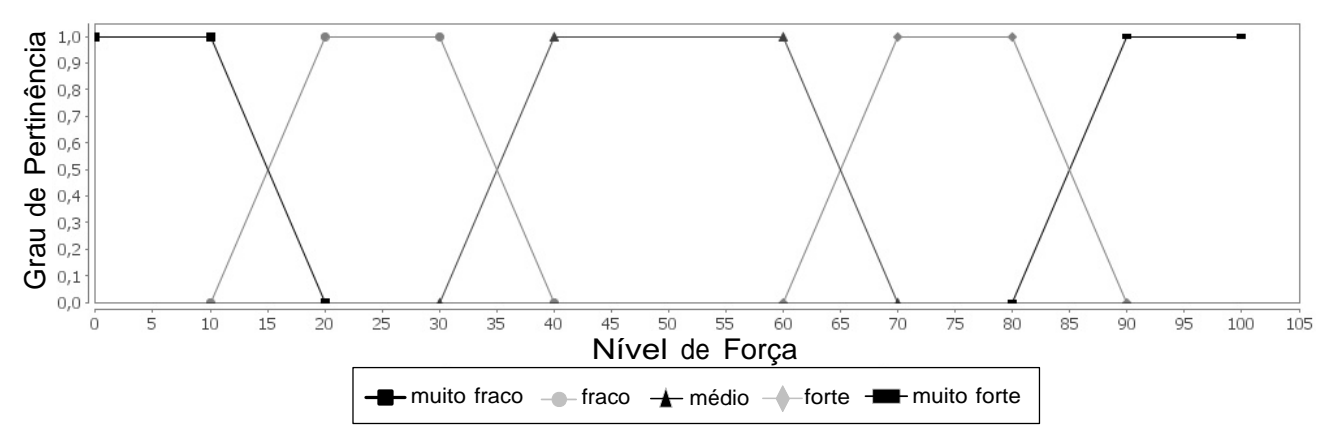

Figura 7. Variável linguística nível de força

entrada, ele utiliza conjuntos clássicos, com as funções características usuais. Assim, para cada conjunto de dados de entrada, somente uma regra da base de conhecimento é ativada.

As funções características dos conjuntos relacionados à variável idade são:

$\varphi_{\text {jovem }}(x)=\left\{\begin{array}{ll}1 & \text { se } x \leq 15 ; \\ 0 & \text { caso contrário }\end{array} \quad \varphi_{\text {adulto }}(x)= \begin{cases}1 & \text { se } 15<x<35 ; \\ 0 & \text { caso contrário }\end{cases}\right.$

$$
\varphi_{\text {velho }}(x)= \begin{cases}1 & \text { se } x \geq 35 \\ 0 & \text { caso contrário }\end{cases}
$$

As funções características dos conjuntos relacionados à variável peso são:

$\varphi_{\text {muito-leve }}(x)=\left\{\begin{array}{l}1 \text { se } x \leq 15 ; \\ 0 \text { caso contrário }\end{array} \varphi_{\text {leve }}(x)=\left\{\begin{array}{l}1 \text { se } 15<x \leq 35 ; \\ 0 \text { caso contrário }\end{array}\right.\right.$ 
Tabela 2. Base de Regras Linguísticas para o Modelo de Percepção Fuzzy

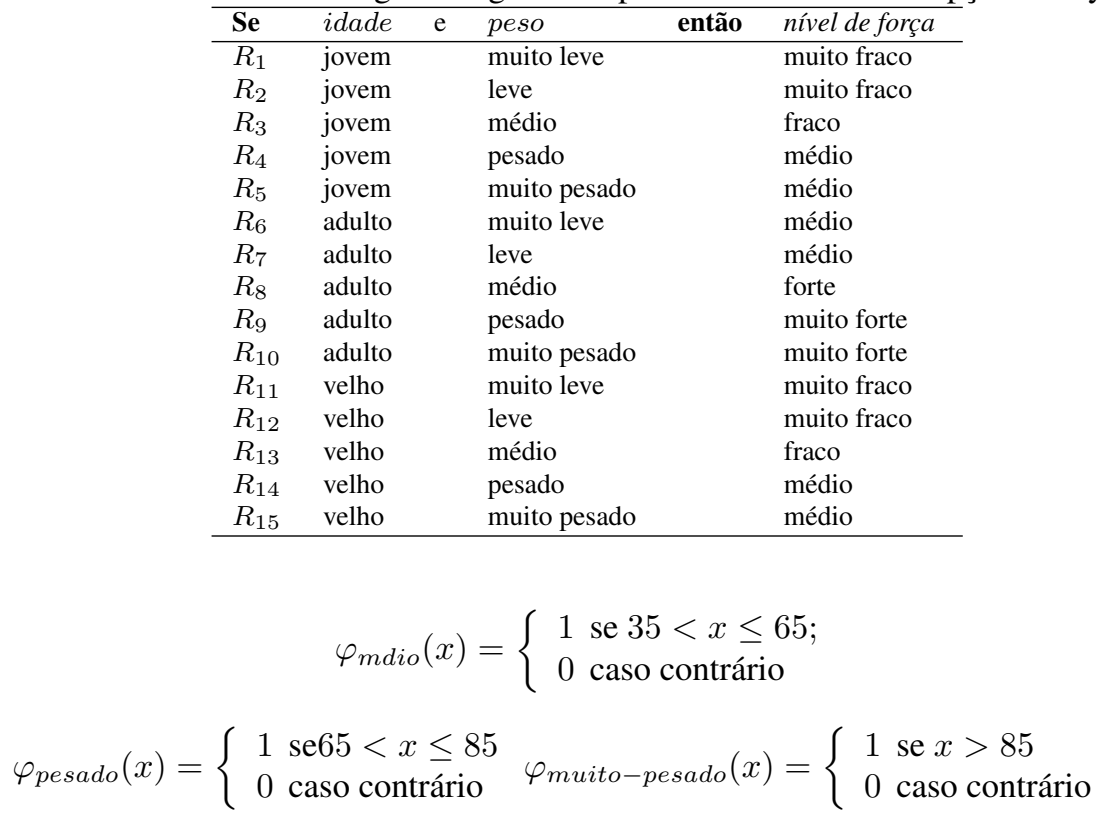

Exemplo 2 Considerando os mesmos dados de entrada (idade, peso) do Ex. 1 e as funções características dadas nas Equações 11 e 13, tem-se que o peso $=84$ e a idade $=16$ são avaliadas exatamente como pesado $\left(\varphi_{\text {pesado }}(84)=1\right)$ e adulto $\left(\varphi_{\text {adulto }}(16)=1\right)$, respectivamente. Neste caso, somente a regra $R_{9}$ da base de regras das Tabelas 2 e 3 é ativada. É imediato que o grau de ativação desta regra é $w_{9}=1$. A saída geral, calculada pela Eq. 7, resulta no valor do nível de força:

$$
z=\frac{w_{9} f_{9}(16,84)}{w_{9}}=\frac{1 \cdot 88}{1}=88
$$

4.1.3 O Agente Predador Guloso (PG). O Predador Guloso (PG) apresenta um mecanismo que sempre ataca qualquer presa que encontrar, sem se preocupar com a probabilidade de sucesso de seus ataques.

\section{Análise das Simulações}

As simulações foram realizadas com objetivo de analisar o comportamento dos diferentes tipos de agentes predadores (PF, PC e PG) em dois tipos de ambientes distintos que 
Tabela 3. Base de regras para o método KTS do modelo de percepção fuzzy

\begin{tabular}{|c|c|c|c|c|c|}
\hline Se & idade & $\mathrm{e}$ & peso & então & força $=f_{i}($ idade, peso $)$ \\
\hline$R_{1}$ & jovem & & muito leve & & $f_{1}(x, y)=\frac{x+y}{2}$ \\
\hline$R_{2}$ & jovem & & leve & & $f_{2}(x, y)=\frac{x+\left(\frac{y}{2}\right)}{2}$ \\
\hline$R_{3}$ & jovem & & médio & & $f_{3}(x, y)=\frac{(x+y)-10}{2}$ \\
\hline$R_{4}$ & jovem & & pesado & & $f_{4}(x, y)=(x-1)+\frac{y}{2}$ \\
\hline$R_{5}$ & jovem & & muito pesado & & $f_{5}(x, y)=x+\frac{y}{2}$ \\
\hline$R_{6}$ & adulto & & muito leve & & $f_{6}(x, y)=\frac{x+y}{2}+25$ \\
\hline$R_{7}$ & adulto & & leve & & $f_{7}(x, y)=\frac{x+y}{2}+30$ \\
\hline$R_{8}$ & adulto & & médio & & $f_{8}(x, y)=\frac{x+\frac{y}{2}+100}{2}$ \\
\hline$R_{9}$ & adulto & & pesado & & $f_{9}(x, y)=\frac{x+y}{4}+63$ \\
\hline$R_{10}$ & adulto & & muito pesado & & $f_{10}(x, y)=\frac{\frac{x}{2}+y}{2}+40$ \\
\hline$R_{11}$ & velho & & muito leve & & $f_{11}(x, y)=\frac{(50-x)+y}{2}$ \\
\hline$R_{12}$ & velho & & leve & & $f_{12}(x, y)=\frac{(50-x)+\frac{y}{2}}{2}$ \\
\hline$R_{13}$ & velho & & médio & & $f_{13}(x, y)=\frac{(50-x)+(y-10)}{2}$ \\
\hline$R_{14}$ & velho & & pesado & & $f_{14}(x, y)=(50-x)+\frac{y}{2}$ \\
\hline$R_{15}$ & velho & & muito pesado & & $f_{15}(x, y)=(50-x)+\frac{y}{2}$ \\
\hline
\end{tabular}

simulam o modelo Presa-Predador Fuzzy: ambiente competitivo e ambiente não competitivo. A implementação foi realizada na plataforma de agentes Jason [2].

Foram realizadas um total de 100 simulações. Em cada simulação, o tempo cresce em unidades discretas de tempo ( 1 unidade de tempo $=1$ movimento do predador). No início de cada simulação, os predadores tem $i d a d e=1$ e peso $=50$, valores que são alterados durante a execução da simulação de acordo com os seguintes parâmetros: taxa de emagrecimento (-0,1 $\mathrm{kg}$ por cada movimento/tempo), taxa de envelhecimento (-0.05 ano para cada movimento/tempo), recompensa (+2 $\mathrm{kg}$ para cada ataque bem sucedido), e punição $(-1 \mathrm{~kg}$ para cada ataque mal sucedido). A simulação termina quando todos os predadores tiverem morrido, ou por fraqueza (peso menor do que $1 \mathrm{~kg}$ ) ou por velhice (idade de 50 anos). ${ }^{5}$

\footnotetext{
${ }^{5}$ Esses valores foram fixados para simplicidade, escolhidos entre as variações testadas por terem apresentado os resultados mais significativos.
} 


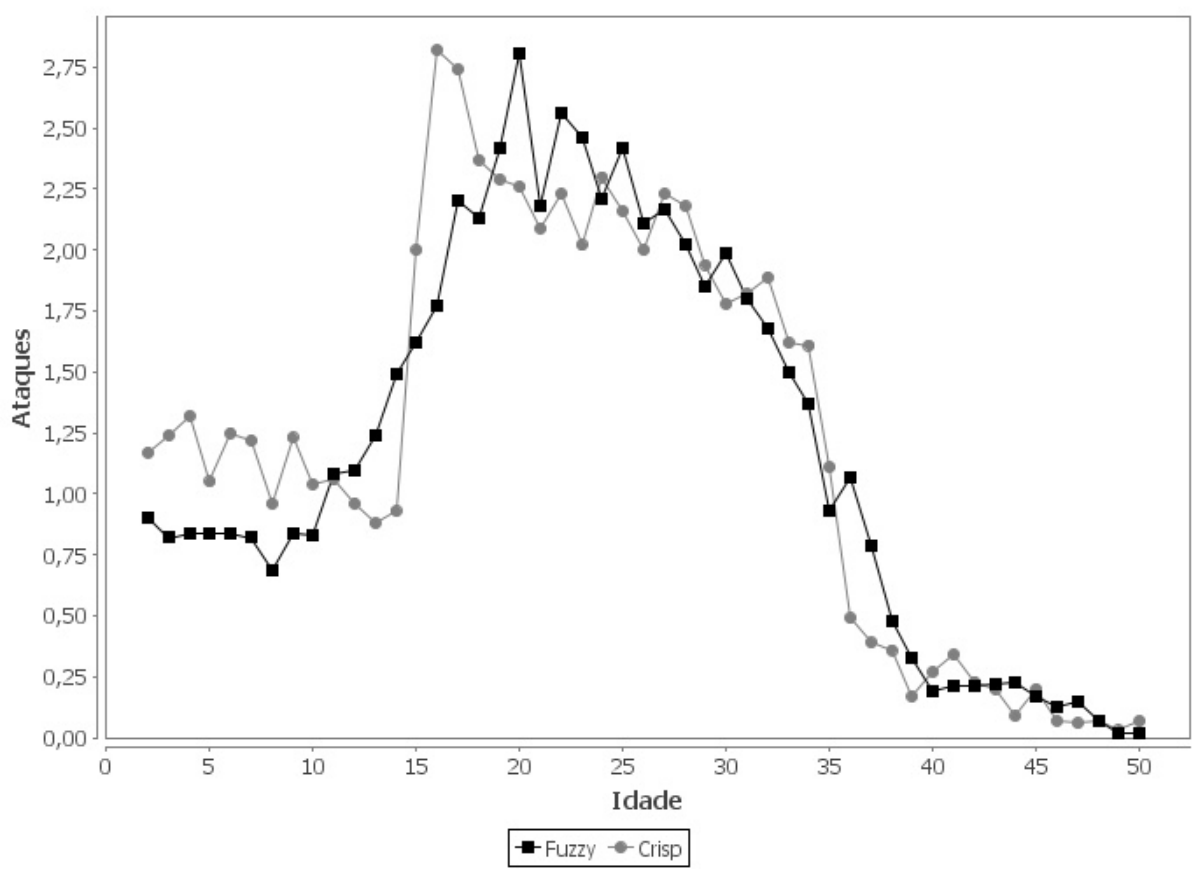

Figura 8. Média de ataques durante a idade $i$

\subsection{Ambiente com Competição}

Consiste de 2 tipos de predadores (PF e PC) e 250 presas distintas (distribuídas aleatoriamente) e que não se movimentam ${ }^{6}$. A cada ataque bem sucedido do agente predador, a presa derrotada morre. Considera-se que não há reprodução de presas e, por esse motivo, a população de presas tende a diminuir na evolução do tempo, diminuindo a probabilidade do predador de encontrar presas a medida que o tempo passa. Por esse motivo, o predador pode ter uma maior perda de peso e, por consequência, de força, a medida que a população de presas diminui. Assim, os dois predadores competem, de certa forma, pelas presas remanescentes no ambiente.

A Figura 8 mostra o número médio de ataques dos predadores a cada intervalo de um ano, mostrando um crescimento significativo para o PC em torno dos 15 anos. Isto acontece porque, antes de 15, o PC considera-se definitivamente jovem (com baixíssimo nível

\footnotetext{
${ }^{6}$ Optou-se por essa simplificação para não introduzir outras variáveis, tais como a destreza da presa em fugir, que pudessem mascarar a avaliação do mecanismo de percepção do agente, direcionado apenas às variáveis peso e idade.
} 


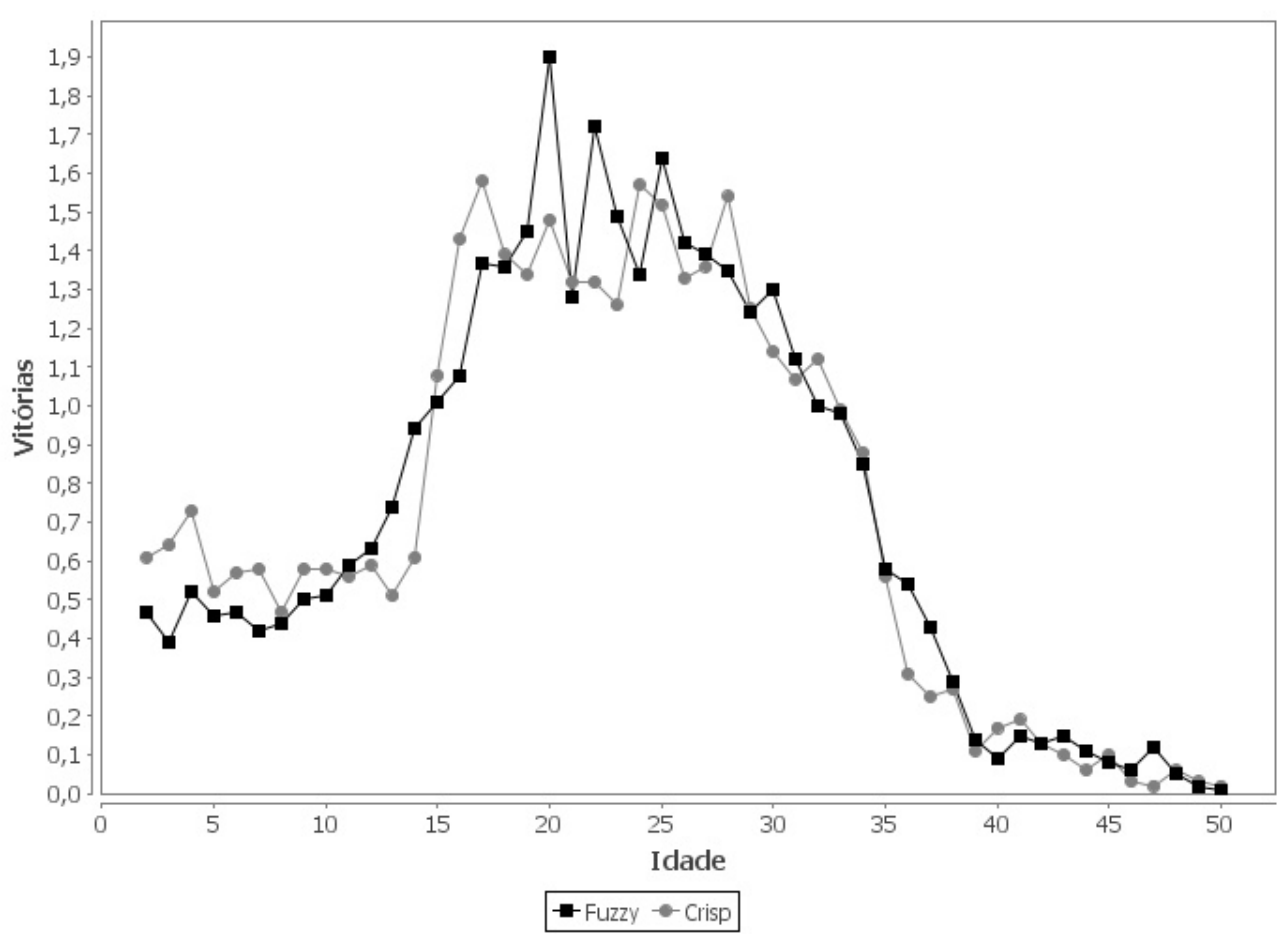

Figura 9. Média de vitórias durante a idade $i$

de força), mas, repentinamente, quando ele atinge 15 anos, o PC conclui que já é um adulto pleno (com altíssimo nível de força). Já o crescimento do número de ataques do PF é gradual, mostrando maior coerência em suas decisões. Por outro lado, seria esperado que o número elevado de ataques permanecesse até a idade de 35, pois é somente após esta idade que o PC se considera definitivamente velho. Entretanto, como a população de presas decresce, o número de ataques de ambos os predadores decresce, mesmo antes da idade de 35 . Em torno de 35, o decréscimo no número de ataques do PC é bem mais abrupto que o descrescimento suave do número de ataques do $\mathrm{PF}$, ao passar de jovem para adulto/velho.

A Figura 9 apresenta o número médio de vitórias dos predadores a cada intervalo de um ano. Há um crescimento significativo no número de vitórias do PC em torno de 15 anos, porque este é o período que, como ele já se considera um adulto pleno, o PC aumenta muito o número de ataques até a idade de 35 , quando se considera definitivamente velho (como discutido no parágrafo anterior). Também, devido ao decréscimo na população de presas, 


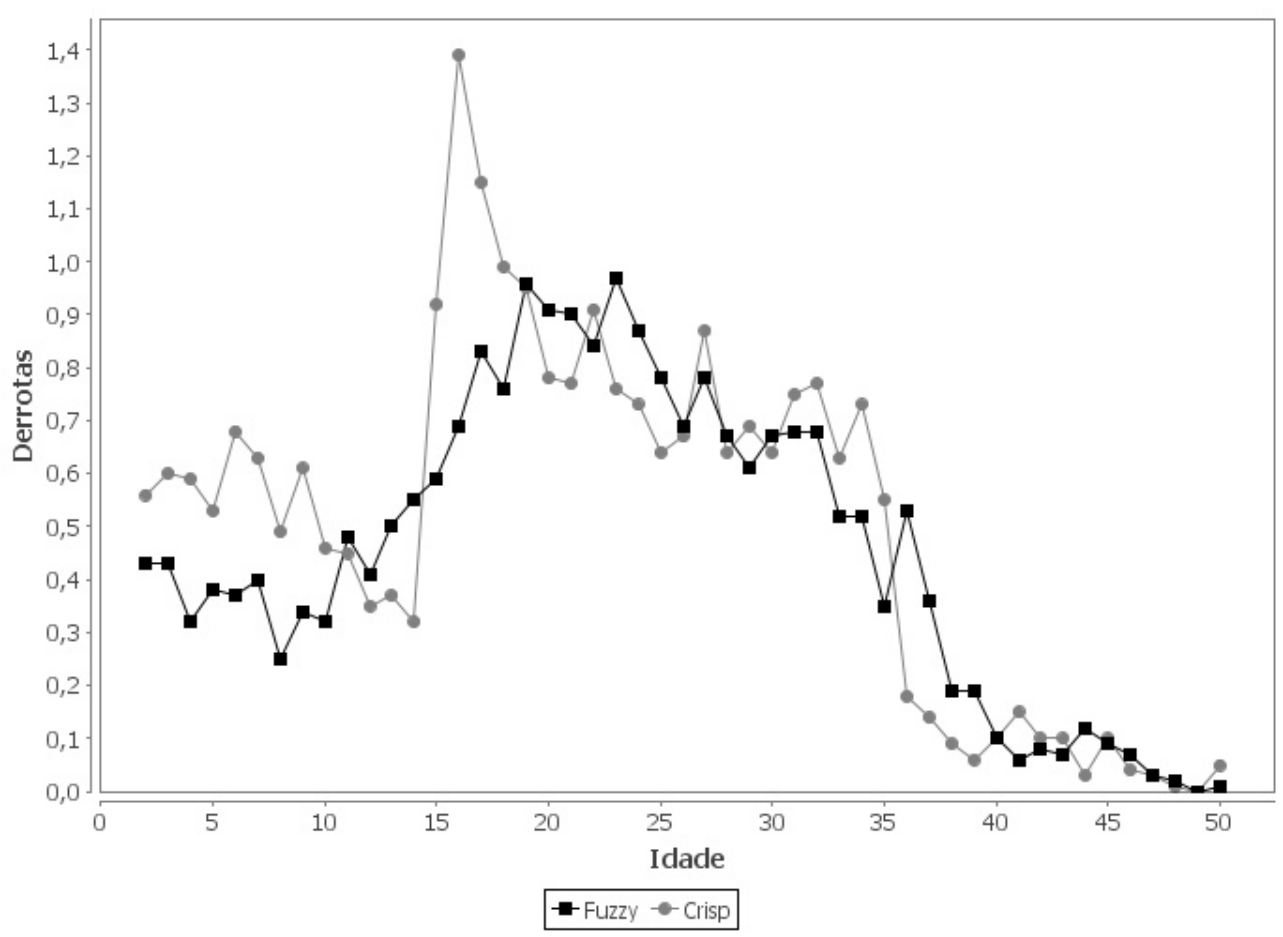

Figura 10. Média de derrotas durante a idade $i$

e, consequentemente, o decréscimo no número de ataques, o número de vitórias também decresce, mesmo antes da idade de 35. Aqui observa-se também que o grafo correspondente ao PF cresce e decresce suavemente, a medida que o PF envelhece, enquanto o grafo do PC cresce em torno de 15 e decresce em torno de 35 , sempre de forma drástica.

Uma análise análoga pode ser realizada com relação ao número médio de derrotas por ano, mostrado na Figura 10, onde o PF apresenta um comportamento mais regular e natural, explicado pela forma como ele percebe a evolução de sua idade e peso.

\subsection{Ambiente sem Competição}

Apresenta 3 tipos de predadores (PF, PC e PG) e 250 presas distintas. Para cada presa que morre por um ataque de predador, uma outra presa similar aparece no ambiente, em uma posição escolhida aleatoriamente. Isto significa que cada predador sempre tem a mesma chance de descobrir presas com as mesmas características para atacar. 


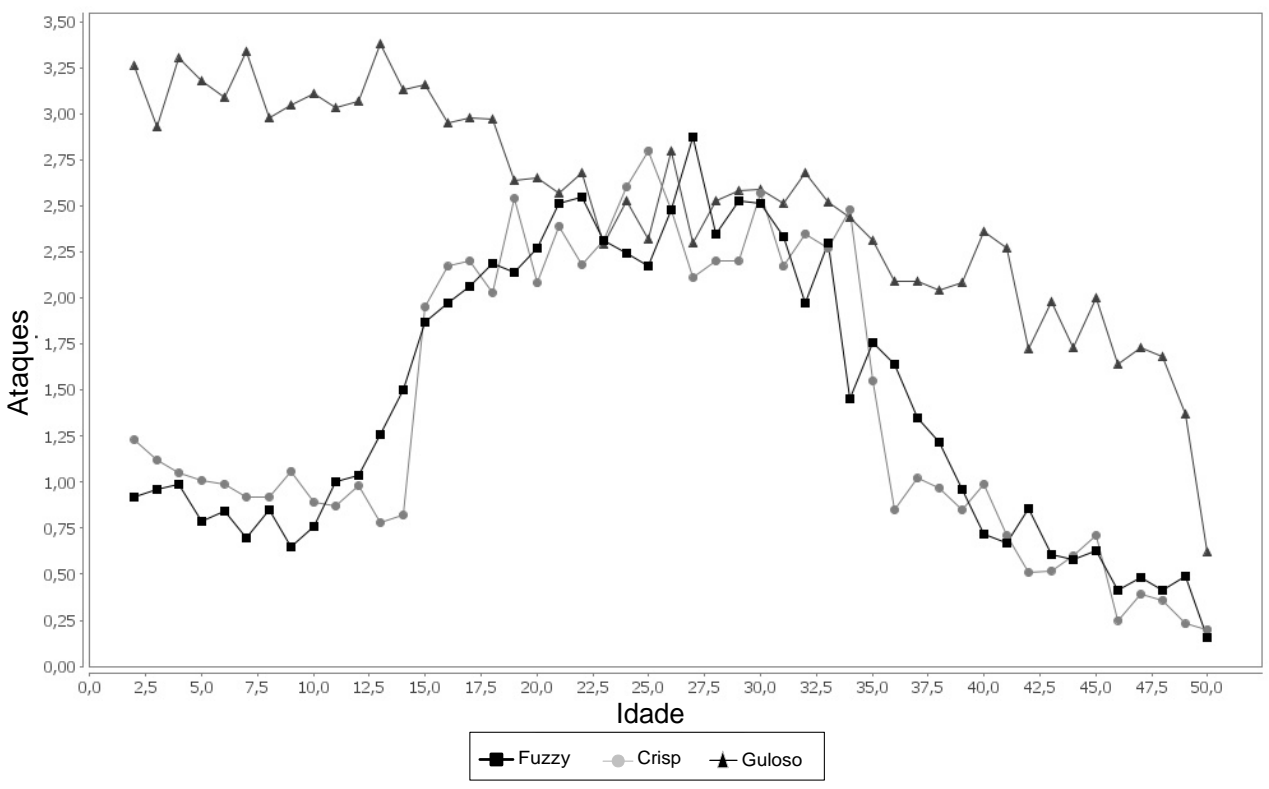

Figura 11. Média de ataques durante a idade $i$

A Figura 11 apresenta a média do número de ataques por ano. Pela mesma razão discutida na Seção 5.1, o número de ataques do PC aumentou muito em torno da idade de 15 anos. Entretanto, como a população de presas é constante ao longo do tempo, o comportamento do PC entre 15 e 35 anos é diferente, sendo que o alto número de ataques do PC permanece até os 35 , quando então decai drasticamente. O comportamento do PF é muito mais natural e coerente, pois observa-se um crescimento gradual no número de ataques à medida que se torna adulto, e, da mesma forma, um decrescimento suave à medida que envelhece. O número alto de ataques do PG durante sua vida é justificado por sua estratégia de "sempre atacar", independente da relação entre o seu nível de força e o da presa. Durante a vida adulta o número de ataques de todos os predadores são similares.

A Figura 12 apresenta a média do número de vitórias dos predadores por ano. Semelhante aos resultados das simulações executadas para o ambiente competitivo e pelas mesmas razões, existe um crescimento abrupto no número de vitórias quando o PC tem idade em torno dos 15 anos. Entretanto, como a população de presas não decresce, o número de vitórias permanece alto até o PC atingir a idade de 35. Depois disso, há um decrescimento radical. Ao contrário, o comportamento do PF é representando por uma grafo que cresce e decresce suavemente. O número alto de ataques do $\mathrm{PG}$ é devido à sua estratégia de ataques. 


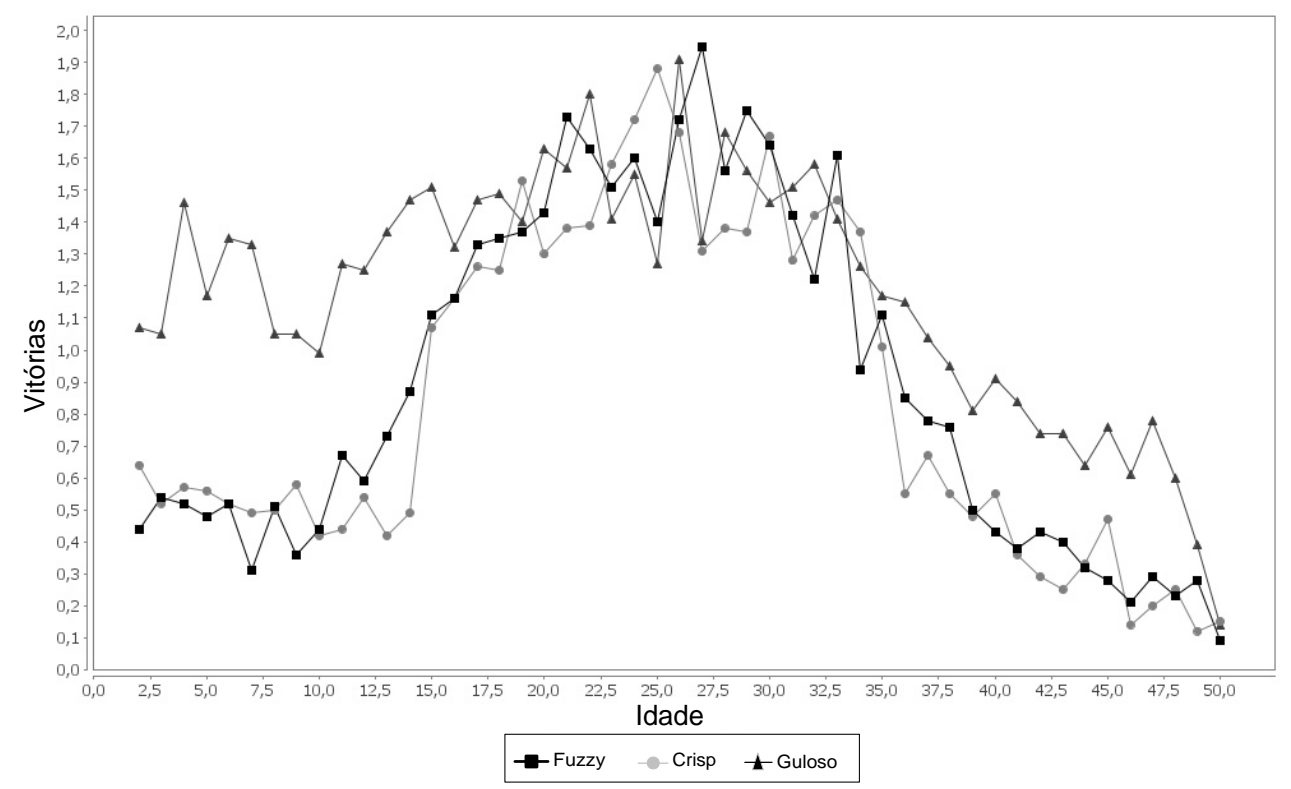

Figura 12. Média de vitórias durante a idade $i$

Durante a vida adulta, os números de vitórias dos 3 tipos de predadores são similares. $\mathrm{O}$ maior número de vitórias, para PC e PF, acontece entre 20 e 33 anos.

Uma análise análoga pode ser realizada com relação ao número médio de derrotas por ano, mostrado na Figura 13, onde o PF apresenta um comportamento mais regular e natural, explicado pela forma como ele percebe a evolução de sua idade e peso. Salienta-se o alto número de derrotas sofridas pelo PG.

A Figura 14 mostra o número médio de ataques acumulados durante toda a vida dos predadores, até atingirem uma certa idade $i$, com $1 \leq i \leq 50$. O PG teve um número médio de ataques acumulados muito maior do que os outros predadores, que apresentaram comportamento similar.

A Figura 15 apresenta o número médio de vitórias acumuladas durante a vida dos predadores, até que atinjam uma idade especificada. O PG teve um número médio de vitórias acumuladas muito maior do que os outros predadores. Entretanto, este número é maior para o PF do que para o PC na medida que os predadores vão envelhecendo.

O número médio de derrotas acumuladas durante a vida dos predadores, até que atinjam uma idade especificada, é mostrado na Figura 16. O PG teve um número médio de derrotas acumuladas muito maior do que os outros predadores. Entretanto, este número é 


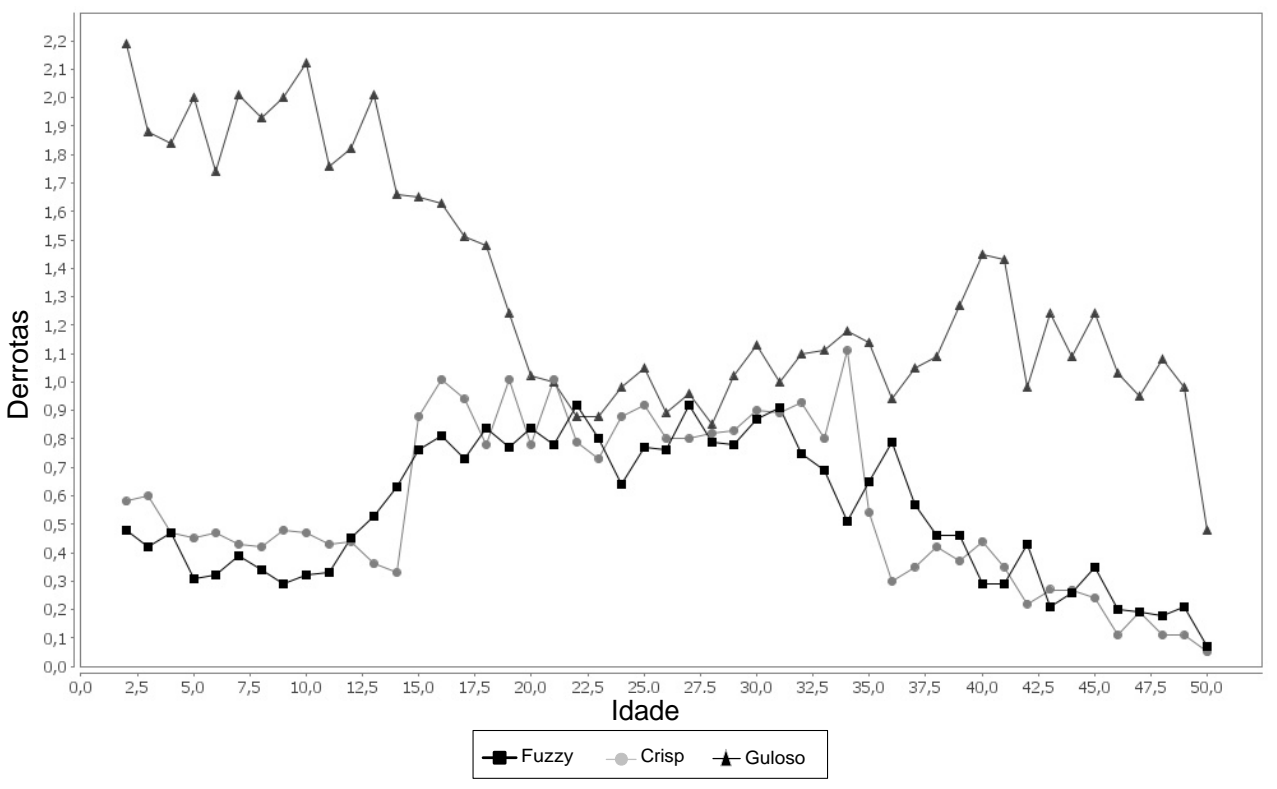

Figura 13. Média de derrotas durante a idade $i$

menor para o PF do que para o PC na medida que os predadores vão envelhecendo.

A Figura 17 (a) mostra o gráfico de barras que representa a média do tempo de vida de cada tipo de predador, ao final das simulações, observando que ao final de uma simulação o predador pode ja ter morrido de fraqueza. O PG é o que apresenta a menor média de vida, enquanto que o PF tem a maior média de vida dentre os predadores. A Figura 17 (b) mostra o gráfico de barras que representa o valor médio do peso de cada tipo de predador no final de suas vidas, considerando todas as simulações. O PG, apesar de ser o predador que possui a menor média de vida, apresenta uma média de peso superior a do PC. De fato, o peso médio do PF no final de sua vida é o maior.

A Figura 18 mostra o gráfico de barras que representa o valor médio do número de ataques, vitórias e derrotas dos predadores durante todas as suas vidas. O PG é o predador que apresenta as maiores médias de ataques, vitórias e derrotas, entretanto, o PG é o único a ter o valor médio de derrotas maior que o de vitórias. O predador Fuzzy com base nas médias de vitórias e derrotas é o agente que apresentou melhor desempenho neste ambiente. 


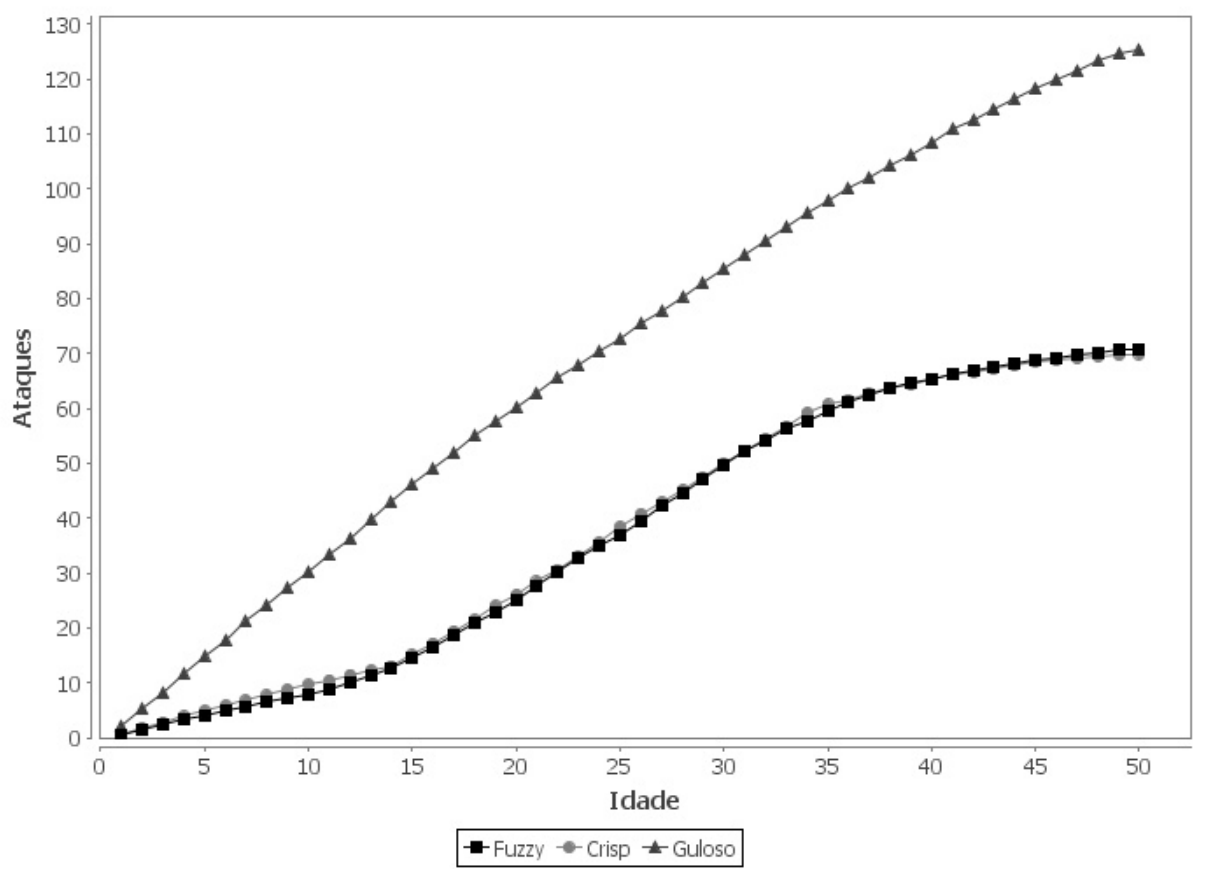

Figura 14. Média de ataques até a idade $i$

\section{Conclusão}

Neste trabalho, foi desenvolvido um Modelo Presa Predador Fuzzy simplificado, com a proposta de um modelo de percepção baseado na LF para um agente BDI, que tem o papel de predador, sendo a implementação realizada na plataforma de agentes Jason.

O trabalho introduziu um modelo de percepção fuzzy para um agente BDI em um ambiente de tarefas com informação imperfeita, inspirado pela análise de um sistema PresaPredador Fuzzy. O objetivo foi analisar a influência da habilidade do agente BDI em simular processos de tomada de decisão em ambientes fuzzy. Para isso, definiu-se um mecanismo de percepção fuzzy diretamente conectado à função de revisão de crenças do agente. $\mathrm{O}$ mecanismo de percepção usa um sistema de inferência KTS, que é dependente de aplicação.

As simulações permitiram obter uma visão geral do comportamento de diferentes predadores (PF, PC e PG) em dois tipos de ambientes Presa-Predador: o ambiente competitivo e o não competitivo. Observou-se que o agente predador Fuzzy apresentou os resultados mais naturais, em comparação com os outros agentes. Embora a diferença entre os resulta- 


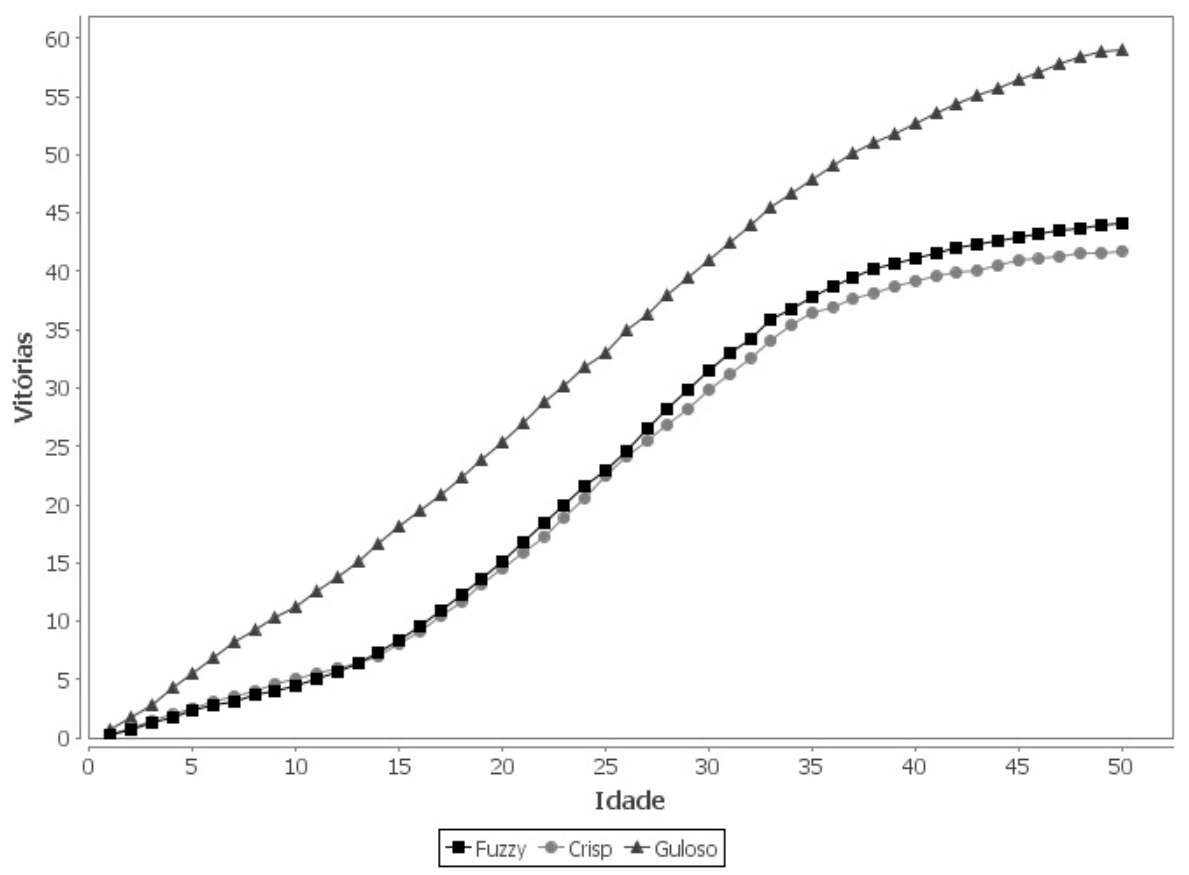

Figura 15. Média de vitórias até a idade $i$

dos obtidos pelos agentes predador Fuzzy e Crisp não tenha sido tão significativa na análise quantitativa realizada, pode-se concluir que o agente predador Fuzzy apresentou um comportamento mais adequado ao ambiente simulado com informação imperfeita, apresentando uma forma mais natural, coerente e realista de comportamento do que os outros agentes.

Assim, é importante ressaltar duas observações sobre os resultados obtidos. Em primeiro lugar, o agente BDI com percepção fuzzy parece ser um bom modelo para ser usado em ambientes com informação imperfeita (como em simulação social). Em segundo lugar, um módulo de percepção difusa pode ser uma boa solução alternativa na concepção de um agente BDI que não seja capaz de perceber a informação do ambiente com precisão.

Em trabalhos futuros, pretende-se considerar um mecanismo de percepção fuzzy para agentes BDI que seja mais independente de aplicação. Para isso, propõe-se utilizar o método de inferência Mamdani no nível dos planos do agente, de tal forma que o mecanismo de percepção execute somente a etapa de fuzzificação sobre os dados de entrada, os quais serão diretamente refletidos no conjunto de crenças do agente, que será então estendido para tratar crenças fuzzy. Serão considerados também cenários onde as informações percebidas pelos 


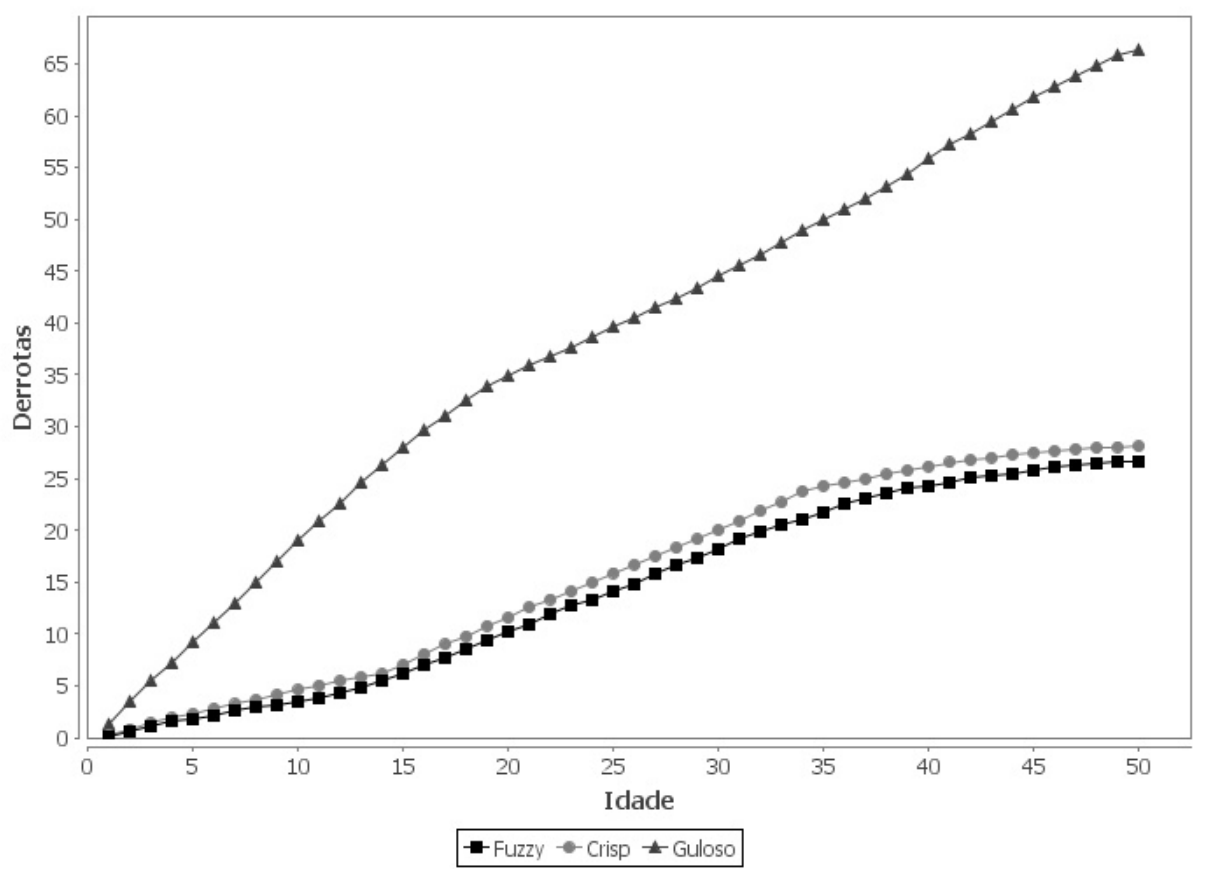

Figura 16. Média de derrotas até a idade $i$

agentes são de natureza subjetiva/qualitativa, tal como na simulação de processos de trocas sociais [20].

Agradecimentos. Este trabalho foi desenvolvido no contexto do Projeto RS-SOC: Rede Estadual de Simulação Social, onde estudam-se modelos de agentes para simulação de aspectos do meio ambiente, que é um ambiente de informação imperfeita. O trabalho é financiado pela FAPERGS/CNPq/PRONEX (Processo 10/0049-7), CNPq (Processos 483257/2009-5, 560118/2010-4, 305131/2010-9, 307185/20079, 304580/2007-4, 559743/2010-6) e CAPES. Os autores agradecem a Rafael Bordini (UFRGS) e aos revisores pelas valiosas sugestões.

\section{Referências}

[1] A. A. Berryman. The origins and evolution of prey-predator theory. Ecology, 73(5):1520-1535, 1992. 
(a)

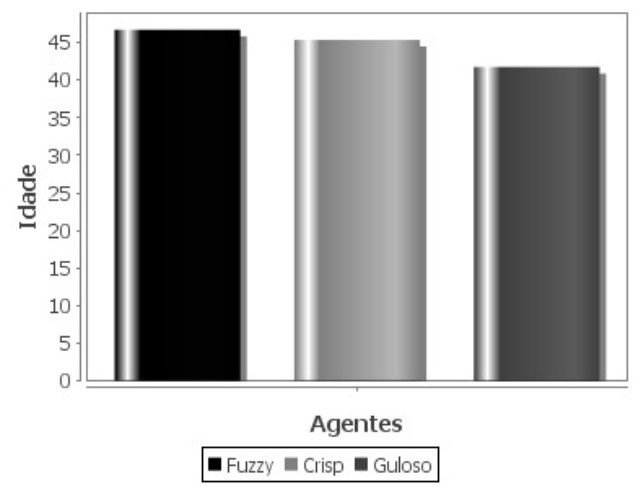

(b)

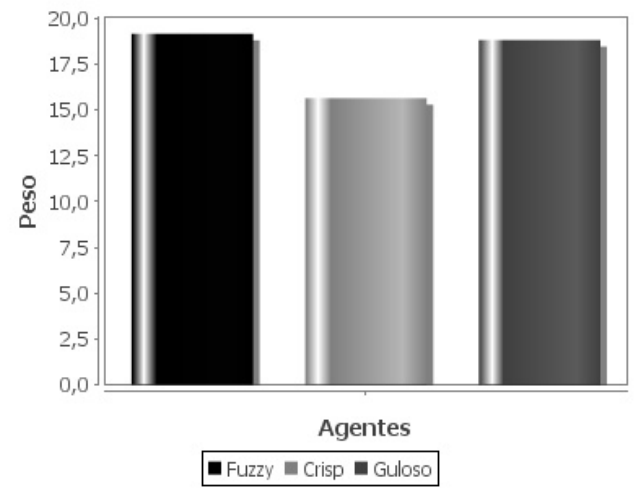

Figura 17. (a) Média de vida dos três tipos de agentes ao final das simulações; (b) Média de peso dos três tipos de agentes ao final das simulações

[2] R. H. Bordini, J. F. Hübner, and M. Wooldridge. Programming Multi-Agent Systems in AgentSpeak using Jason. Wiley, New Jersey, 2007.

[3] A. Casali, L. Godo, and C. Sierra. Graded BDI models for agent architectures. In Computational Logic in Multiagent Systems, number 3487 in LNAI, pages 126-143. Springer, Berlin, 2005.

[4] A. Casali, L. Godo, and C. Sierra. Modeling travel assistant agents: a graded BDI approach. In Artificial Intelligence in Theory and Practice, volume 217 of IFIP, pages 415-424. Springer, Berlin, 2006.

[5] P. Costa and R. R. McCrae. Revised NEO Personality Inventory (NEO-PI-R) and NEO Five-Factor Inventory (NEO-FFI). Professional Manual. Psychological Assessment Resources, Inc, Odessa, 1992.

[6] F. Cuesta and A. Ollero. Intelligent control of mobile robots with fuzzy perception. In Intelligent Mobile Robot Navigation, volume 16 of Springer Tracts in Advanced Robotics, pages 79-122. Springer, Berlin, 2005.

[7] E. del Acebo and J. L. de la Rosa. A fuzzy system based approach to social modeling in multi-agent systems. In Proceedings of the International Conference on Autonomous Agents and Multiagent Systems, pages 463-464. ACM, 2002.

[8] G. P. Dimuro, A. V. Santos, G. P. Bedregal, and A. C. R. Costa. Fuzzy evaluation of social exchanges between personality-based agents. In L. S. Lopes, N. Lau, P. Mariano, 


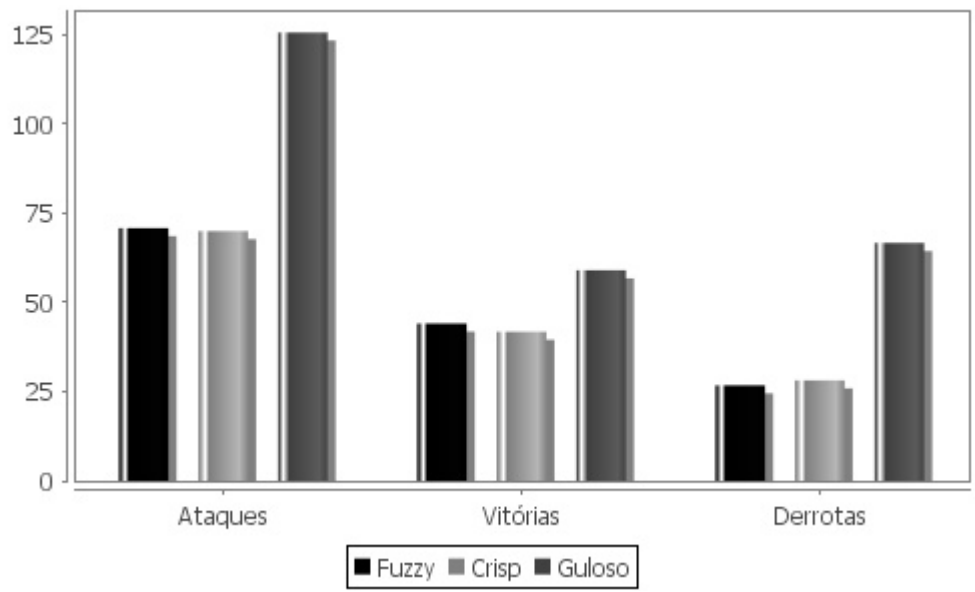

Figura 18. Média de ataques, vitórias e derrotas dos predadores ao final das simulações

and L. M. Rocha, editors, New Trends In Artificial Intelligence, Procedings of the 14th Portuguese Conference on Artificial Intelligence, pages 451-462, Aveiro, 2009. APIA.

[9] H. Fort and N. Pérez. The fate of spatial dilemmas with different fuzzy measures of success. Journal of Artificial Societies and Social Simulation, 8(3), 2005.

[10] N. Ghasem-Aghaee and T. I. Ören. Towards fuzzy agents with dynamic personality for human behavior simulation. In Proceedings of the 2003 Summer Computer Simulation Conference, Montreal, July 20-24, 2003, pages 3-10, San Diego, 2003. SCS.

[11] T. Grüne-Yanoff. The explanatory potential of artificial societies. Synthese, 169(3):3, 2006.

[12] L. Hai-bo, G. Guo-Chang, S. Jing, and F. Yan. AUV fuzzy neural BDI. Marine Science and Application, 4(3):37-41, 2007.

[13] S. Hassan, L. Garmendia, and J. Pavón. Agent-based social modeling and simulation with fuzzy sets. In E. Corchado, J. M. Corchado, and A. Abraham, editors, Innovations in Hybrid Intelligent Systems, number 44 in Advances in Soft Computing, pages 40-47. Springer, Berlin, 2008.

[14] S. Hassan, M. Salgado, and J. Pavon. Friends forever: Social relationships with a fuzzy agent-based model. In Hybrid Artificial Intelligence Systems, number 5271 in LNCS, pages 523-532. Springer, Berlin, 2008. 
[15] P. J. Howard and J. M. Howard. The BIG FIVE Quickstart: An Introduction to the FiveFactor Model of Personality for Human Resource Professionals. Center for Applied Cognitive Studies (CentACS), Charlotte, 1995.

[16] P. Lokuge and D. Alahakoon. Decisions based upon multiple values: the BVG agent architecture. In N. R. Pal, N. Kasabov, R. K. Mudi, S. Pal, and S. K. Parui, editors, Neural Information Processing, number 3316 in LNCS, pages 941-946. Springer, Berlin, 2004.

[17] S. A. Long and A. C. Esterline. Fuzzy BDI architecture for social agents. In N. R. Pal, N. Kasabov, R. K. Mudi, S. Pal, and S. K. Parui, editors, Proceedings of the IEEE Southeastcon 2000, pages 68-74, Los Alamitos, 2000. IEEE.

[18] H. Mobahi and S. Ansari. Fuzzy perception, emotion and expression for interactive robots. In Proceedings of the IEEE International Conference on Systems, Man and Cybernetic (SMCC03), volume 4, pages 3918-3923, Washington, 2003.

[19] M. S. Peixoto, L. C. Barros, and R. C. Bassanezi. Predator-prey fuzzy model. Ecological Modelling, 124(1):39-44, 2008.

[20] D. R. Pereira, L. V. Gonçalves, G. P. Dimuro, and A. C. R. Costa. Towards the selfregulation of personality-based social exchange processes in multiagent systems. In G. Zaverucha and A. L. Costa, editors, Advances in Artificial Intelligence, number 5249 in LNAI, pages 113-123. Springer, Berlin, 2008.

[21] A. S. Rao and M. P. Georgeff. Modeling rational agents within a BDI-architecture. In R. Fikes and E. Sandewall, editors, Proceedings of the 2nd International Conference on Principles of Knowledge Representation and Reasoning, pages 473-484, San Mateo, 1991. Morgan Kaufmann.

[22] S. Rossiter, J. Noble, and K. R. W. Bell. Social simulations: Improving interdisciplinary understanding of scientific positioning and validity. Journal of Artificial Societies and Social Simulation, 13(1):10, 2010.

[23] J. Sabater-Mir, M. Paolucci, and R. Conte. Repage: REputation and imAGE among limited autonomous partners. Journal of Artificial Societies and Social Simulation, 9(2):539-555, 2009.

[24] E. Sabeur and G. Denis. Human behavior and social network simulation: Fuzzy sets/logic and agents-based approach. In Proceedings of the 2007 Spring Simulation Multi-Conference, Norfolk, 2007, pages 102-109, San Diego, 2007. SCS.

[25] S. Shen, G. M. P. O'Hare, and R. Collier. Decision-making of BDI agents, a fuzzy approach. In Proceedings of the 4th International Conference on Computer and Information Technology, pages 1022 - 1027, Washington, 2004. IEEE. 
[26] S. Shen, G. M. P. O'Hare, and M. J. O'Grady. Fuzzy-set-based decision making through energy-aware and utility agents within wireless sensor networks. Artificial Intelligence Review, 27(2-3):165-187, 2008.

[27] Y. Takagi and M. Sugeno. Fuzzy identification of systems and its applications to modeling and control. IEEE Transactions on Systems, Man and Cybernetics, 15(1):116-132, 1985.

[28] L. A. Zadeh. Fuzzy sets. Information and Control, 8:338-353, 1965.

[29] L. A. Zadeh. Is there a need for fuzzy logic? Information Sciences, 178(13):2751-2779, 2008.

[30] T. I. Ören and N. Ghasem-Aghaee. Personality representation processable in fuzzy logic for human behavior simulation. In Proceedings of the 2003 Summer Computer Simulation Conference, Montreal, July 20-24, 2003, pages 11-18, San Diego, 2003. SCS. 